\title{
Hiv/Aids Awareness as a Predictor of University Students' Dating Behaviour in South - Western Nigeria
}

\author{
Arogundade O. T., Faloore O. O.*
}

Redeemer'S University, Mowe, Ogun State, Nigeria

\begin{abstract}
Adolescents' social relationships have the potential to enhance or impede the successful development of their heterosexual relationship, thus, the need to examine the relationship between HIV/AIDS awareness and dating behaviour among undergraduate students. The participants in the study were one thousand six hundred undergraduates (1600: $\mathrm{M}=800$ and $\mathrm{F}=800$ ) randomly selected from eight universities in South-western part of Nigeria, in the age range 16 to 30 years old. The AIDS Awareness/ Attitude Scale (AAS) and Dating Behaviour Questionnaire (DBQ) were used to collect data. The data were analyzed with Statistical Package for Social Sciences (SPSS) with emphasis on simple percentages, Multiple Regression Analysis, and Analysis of Variance (ANOVA). The results confirm that HIV/AIDS awareness account for a significant two percent $(2 \%)$ variance in university students' dating behaviour. The implication of the result for understanding the heterosexual behaviour of undergraduates and minimizing their indecent relationships were discussed and recommendations made accordingly.
\end{abstract}

Keywords HIV/AIDS, Awareness, Attitude, University Students, Dating Behaviour

\section{Introduction}

The issues of dating and mate-seeking behaviour of $\mathrm{Ni}$ gerian youth are rapidly changing with the country's modernization and globalization. Dating is often described as a form of courtship, that may include any social activity undertaken by, typically, two person with the aim of each assessing the others suitability as a partner in an intimate relationship or as a spouse. The increased dating activity has possibility of promoting the risk factor of contacting HIV/ AIDS in that dating bears the notion of frequent partner change which often leads to establishing multiple sexual intimacy and intercourse and in most cases are unprotected and can result into contacting sexually transmitted diseases and HIV/ AIDS.

Studies have shown that casual heterosexual relationship is one of the major means of spreading HIV/AIDS following the decline in its transmission through blood products (Taylor, 1990; Uwalaka and Matsuo, 2002). Thus, casual dating behavior and unprotected sexual relationships among the youths will have influence on the spread of HIV/AID. Globally, young people have been identified to be at special risk of HIV infection due to their unprotected sexual intercourse and multiple sexual partners. Roscoe and Kruger (1990) studied the level of HIV/AIDS awareness among

* Corresponding author:

yinkalola@yahoo.com (Faloore O. O.)

Published online at http://journal.sapub.org/ijpbs

Copyright (C) 2012 Scientific \& Academic Publishing. All Rights Reserved junior and senior college students and found that while $90 \%$ of the participants answered two-thirds of the questions about HIV/ AIDS correctly, an item concerning the cause of AIDS was the only question answered incorrectly by less than $50 \%$ of the participants. However, Fantahum \& Chala, (1996) found low levels of HIV/AIDS awareness among college students in Ethiopia reporting that a large proportion of their participants do not have accurate knowledge of the causes and prevention of HIV/AIDS transmission.

In consonance with the foregoing line of argument, Kole, Singh, Panwar (2004) examined dating and mate seeking behaviour of Indian youth in the context of HIV/AIDS and found that ninety six percent $(96 \%)$ youth were seeking mate from their own city and forty six percent $(46 \%)$ get a regular partner. The ratio of male to female in the message board or chat room is $3: 1$. Eighty seven percent $(87 \%)$ females and fifty four $(54 \%)$ males get a regular partner and have continuous interaction through mails, letters, greetings or telephone. Further analysis showed twenty four percent (24\%) females and thirty one percent (31\%) males have physically met more than one partner. The mean duration of relationship is 10.2 months, nineteen percent (19\%) boys and nine percent (9\%) girls end up in having sexual intercourse and in fifty four percent (54\%) cases; the intercourse took place without a condom showing they are less concerned about the associated consequences.

Also, Sprecher (1990) studied the impact of the threat of HIV/AIDS on heterosexual dating relationships among adolescents and found that majority of the dating partners reported discussing HIV/AIDS in their relationship. The 
participants, however, reported only a small amount of change in their sexual behaviours as a result of the threat of HIV/AIDS, with females reporting that they engaged in more cautious behaviours than their males counterparts. A majority of the participants believed that they would stay with their partner if he or she became HIV-infected while they also believed that their partner would stay with them if they became HIV-infected. The major predictor of both willingness to stay in a relationship with an infected partner and the expectation that one's partner would stay involved was commitment to the relationship.

Corroborating the above assertion and highlighting the steady rise in the number of people living with HIV/AIDs in Nigeria. Ologun (2002) and Smith (2004) in their studies concluded that HIV/AIDs found that HIV/AIDS has been discovered in all the states of Nigeria and that Nigeria is rated second in HIV infection in the sub-Saharan Africa. Also, in their submissions, they ranked in order of importance factors influencing the spread of HIV/AIDs in Nigeria and other parts of Africa as pre-marital sex among youth, poverty and ignorance about the causes and prevention of HIV/AIDs.

However, some of the above reviewed studies confirm that adolescent females are more likely to reduce the number of times they engage in premarital sexual behavior in order to avoid getting pregnant rather than avoiding sexually transmitted infections (STIs). Although literatures on health behaviour have focused on the role of individuals' perceived susceptibility to HIV/AIDS as a motivator of behavioural change (Aiken, Gerend \& Jackson, 2001; Fishbein, Triandis, Kanfer, Becker, Middlestadt \& Eichler, 2001). But none of the studies has specifically focused on the role of HIV/AIDS as a predictor of variance in undergraduates dating behavior. In the light of the above, this study investigates the effects of awareness of HIV/AIDS of undergraduates on their dating pattern. Thus, the following hypotheses were tested.

1. There will be a significant difference between the dating behaviour of undergraduates that have adequate knowledge of the occurrence and prevalence of HIV/AIDS and their counterparts that do not have adequate knowledge of same.

2. There will be a significant difference between the dating behaviour of undergraduates that have accurate awareness of mode of transmitting HIV/AIDS infection and their counterparts that have inaccurate awareness of mode of transmitting HIV/AIDS.

3. There will be a significant difference between the dating behaviour of undergraduates that have adequate awareness of the effects and consequences of HIV/AIDS and their counterparts that have inadequate awareness of effects and consequences of HIV/AIDS.

4. There will be a significant difference between dating behaviour of undergraduates that have positive attitude towards preventing HIV/AIDS and their counterparts that have negative attitude to same.

5. There will be a significant difference between dating behaviour of undergraduates who scored high on all the subscales of general HIV/AIDS awareness and their counterparts that scored low on all the subscales of general HIV/AIDS awareness

6. There will be a significant positive relationship between HIV/AIDS awareness subscales and dating behaviour.

7. HIV/AIDS awareness will significantly predict variance in undergraduate dating behaviour.

\section{Material and Methods}

\section{Research Design}

The research design was a survey cross-sectional design. The rationale for the adoption of this design hinges on the fact that the dependent variables (dating behavior) being considered in the study has already occurred. Thus, the researcher did not manipulate any variable rather the variables of interest were sought for in the participants using inventories.

The participants in the study were one thousand and six hundred (1600, $\mathrm{M}=800 \& \mathrm{~F}=800)$ undergraduates in age range 16 to 30 years old randomly selected from eight universities in the South-Western part of Nigeria. These are Redeemers University (RUN), Ogun state; University of Lagos (UNILAG), Akoka; Lagos State, Lagos State University (LASU), Ojo, Lagos State; Federal University of Technology Akure, (FUTA) Ondo State; University of Ado Ekiti, Ado Ekiti (UNAD) Ekiti State; Olabisi Onabanjo University(OOU), Ago-Iwoye, ogun State; Obafemi Awolowo University (OAU), Osun State and University of Ibadan, (UI) Oyo State.

The rationale for selecting the above universities as samples is to give a fair representation of the population of the Private, Federal and State owned Universities in the SouthWestern part of Nigeria.

\section{Instruments}

1. The Awareness/ Attitude to AIDS Scale (AAS) is a 50-item inventory developed by Omoluabi (1995) to quantitatively evaluate the following components of the awareness- attitude, perception and predisposition to HIV/AIDS.

The psychometric properties were provided by Omoluabi (1995) and Vincent (1995). The test-retest reliability coefficients were obtained and the concurrent validity of the AAS subscales with Osgood Semantic Differential scales was obtained. The norms or mean scores are the basis for interpreting the scores of the participants. Scores equal to or higher than the norms indicate that the participant has a high level of awareness, knowledge and accurate information about HIV/AIDS.

2. Dating Behaviour Questionnaire (DBQ) is a 23 -item inventory designed to access social competence in heterosexual situations.

The psychometric properties of the scale were obtained by the researchers. The test-retest reliability of 0.35 was obtained as well as concurrent validity coefficient of 0.18 by correlating Dating Behaviour scales with Assertion sub- 
scales and index of self-esteem (Hudson, 1982) respectively. Data Analysis

The data collected were analyzed with Statistical Package for Social Sciences (SPSS) with emphasis on simple percentages, Multiple Regression Analysis, and Analysis of Variance (ANOVA).

\section{Results and Discussion}

These results of the processed primary data collected were presented systematically and used accordingly to answer the research questions as well to test the hypotheses.

\section{Testing Hypothesis 1}

There will be a significant difference between the dating behaviour of undergraduates that have adequate knowledge of the occurrence and prevalence of HIV/AIDS and their counterparts that have inadequate knowledge of same.

Table 1. Summary of Independent t-test showing the differences in undergraduates dating behavior on the basis of their knowledge of the occurrence and prevalence of HIV/AIDS

\begin{tabular}{|c|c|c|c|c|c|c|}
\hline Variable & Source & $\mathrm{N}$ & $X$ & $\mathrm{SD}$ & $\mathrm{t}$ & Sig. \\
\hline \multirow{2}{*}{$\begin{array}{c}\text { Knowledge of } \\
\text { HIV/AIDS }\end{array}$} & Low & 540 & 68.77 & 11.66 & \multirow{2}{*}{4.82} & $<0.05^{*}$ \\
\cline { 2 - 5 } & High & 653 & 72.10 & 12.06 & & \\
\hline
\end{tabular}

Table 1 above shows that there is a significant difference in undergraduates dating behaviour on the basis of their knowledge of the occurrence and prevalence of HIV/AIDS. Where $\mathrm{t}=4.82$, df $1191, \mathrm{p}<0.05$ level of significant.

\section{Testing Hypothesis 2}

There will be a significant difference between the dating behaviour of undergraduates that have accurate awareness of mode of transmitting HIV/AIDS infection and their counterparts that have inaccurate awareness of mode of transmitting HIV/AIDS.

Table 2. Summary of Independent t-test showing the differences in undergraduates' dating behavior on the basis of awareness of mode of transmitting HIV/AIDS infection

\begin{tabular}{|c|c|c|c|c|c|c|}
\hline Variable & Source & $\mathrm{N}$ & $\boldsymbol{X}$ & $\mathrm{SD}$ & $\mathrm{t}$ & Sig. \\
\hline \multirow{2}{*}{$\begin{array}{c}\text { Infection } \\
\text { awareness }\end{array}$} & Low & 602 & 68.82 & 11.93 & \multirow{2}{*}{2.09} & \multirow{2}{*}{$<0.05$} \\
\cline { 2 - 6 } & High & 416 & 71.42 & 12.13 & & \\
\hline
\end{tabular}

Table 2 above shows that there is a significant difference in undergraduates dating behaviour on the basis of their awareness of mode of contracting of HIV/AIDS. Where $\mathrm{t}=2.09, \mathrm{p}<0.05$ level of significant.

\section{Testing of Hypothesis 3}

There will be a significant difference between the dating behaviour of undergraduates that have adequate awareness of the effects and consequences of HIV/AIDS and their counterparts that have inadequate awareness of effects and consequences of HIV/AIDS.

Table 3. Summary of Independent t-test showing the differences in undergraduates' dating behavior on the basis of their awareness of the effects and consequences of HIV/AIDS

\begin{tabular}{|c|c|c|c|c|c|c|}
\hline Variable & Source & $\mathrm{N}$ & $\boldsymbol{X}$ & $\mathrm{SD}$ & $\mathrm{t}$ & Sig. \\
\hline \multirow{2}{*}{$\begin{array}{c}\text { Awareness effects } \\
\text { of HIV/AIDS }\end{array}$} & Low & 672 & 70.24 & 11.08 & \multirow{2}{*}{1.38} & \multirow{2}{*}{$>0.05$} \\
\cline { 2 - 6 } & High & 422 & 71.23 & 12.20 & & \\
\hline
\end{tabular}

Table 3 above shows that there is no significant difference in undergraduates dating behaviour on the basis of their awareness of the effects and consequences of HIV/AIDS; where $t=1.38, p>0.05$ level of significant.

\section{Testing of Hypothesis 4}

There will be a significant difference between dating behaviour of undergraduates that have positive attitude towards preventing HIV/AIDS and their counterparts that have negative attitude.

Table 4. Summary of Independent t-test showing the differences in the attitude towards preventing HIV/AIDS and dating behaviour

\begin{tabular}{|c|c|c|c|c|c|c|}
\hline Variable & Source & $\mathrm{N}$ & $\boldsymbol{X}$ & $\mathrm{SD}$ & $\mathrm{t}$ & Sig. \\
\hline $\begin{array}{c}\text { Attitude towards } \\
\text { preventing HIV/AIDS }\end{array}$ & Low & 508 & 69.55 & 11.12 & \multirow{2}{*}{2.23} & \multirow{2}{*}{$<0.05^{*}$} \\
\cline { 2 - 6 } & High & 775 & 71.01 & 11.98 & & \\
\hline
\end{tabular}

Table 4 above shows that there is a significant difference in undergraduates dating behaviour on the basis of their attitude towards preventing HIV/AIDS; where $\mathrm{t}=2.23$, $\mathrm{p}<0.05$ level of significant.

\section{Testing of Hypothesis 5}

There will be a significant difference between dating behaviour of undergraduates that have adequate overall awareness of HIV/AIDS and their counterparts that have inadequate overall awareness of HIV/AIDS.

Table 5. Summary of Independent t-test showing the differences in undergraduates' dating behaviour on the basis their overall awareness of HIV/AIDS

\begin{tabular}{|c|c|c|c|c|c|c|}
\hline Variable & Source & $\mathrm{N}$ & $\boldsymbol{X}$ & $\mathrm{SD}$ & $\mathrm{t}$ & Sig. \\
\hline \multirow{2}{*}{$\begin{array}{c}\text { Overall awareness } \\
\text { of AIDS }\end{array}$} & Low & 531 & 68.71 & 10.84 & \multirow{2}{*}{4.63} & $<0.05$ \\
\cline { 2 - 5 } & High & 673 & 71.89 & 12.60 & $<3$ \\
\hline
\end{tabular}

Table 5 above reveals that there is a significant difference in undergraduates dating behaviour on the basis of their general awareness of HIV/AIDS (where $t=4.63$, $p<0.05$ level of significant.

\section{Testing of Hypothesis 6}

There will be a significant positive relationship between HIV/AIDS awareness subscales and dating behaviour.

Table 6. Matrix of Correlation showing relationship between HIV/AIDS Awareness and Dating Behaviour

\begin{tabular}{|c|c|c|c|c|c|}
\hline Var & 1 & 2 & 3 & 4 & 5 \\
\hline 1 & - & & & & \\
\hline 2 & 0.17 & & & & \\
\hline 3 & 0.14 & 0.17 & & & \\
\hline 4 & 0.81 & 0.13 & 0.31 & & \\
\hline 5 & 0.98 & 0.98 & 0.49 & 0.86 & - \\
\hline
\end{tabular}

(Where 1. Knowlegde of HIV/AIDS; 2. Infection awareness; 3. Awareness effects of HIV/AIDS; 4. Prevention and 5. Dating

The Table of Pearson Product Moment Correlation Matrix shows that there are significant positive relationships between dating behaviour and the three subscales of HIV/AIDS Awareness, namely- knowledge of the occurrence and prevalence of HIV/AIDS (0.98), awareness of mode of transmitting HIV/AIDS (0.98) and attitude towards preventing HIV/AIDS (0.86). Only the subscale of awareness of the effects and consequences of HIV/AIDS was not significantly related to dating behaviour. 


\section{Testing of Hypothesis 7}

HIV/AIDS awareness will significantly predict variance in undergraduate dating behaviour.

Table 7. Multiple Regression analysis Model showing the influence of HIV/AIDS Awareness on Dating Behaviour

\begin{tabular}{|c|c|c|c|c|c|c|}
\hline Variable & $\mathrm{B}$ & $\mathrm{t}$ & $\mathrm{R}$ & $\mathrm{R} 2$ & $\mathrm{~F}$ & $\mathrm{P}$ \\
\hline $\begin{array}{c}\text { Knowlegde of } \\
\text { HIV/AIDS }\end{array}$ & 0.07 & 3.04 & & & & \\
\hline $\begin{array}{c}\text { Infection } \\
\text { awareness }\end{array}$ & 0.08 & 3.40 & 0.15 & 0.02 & 9.28 & 0.05 \\
\hline $\begin{array}{c}\text { Awareness } \\
\text { effects of AIDS }\end{array}$ & 0.03 & 0.12 & & & & \\
\hline $\begin{array}{c}\text { Prevention of } \\
\text { HIV/AIDS }\end{array}$ & 0.82 & 3.12 & & & & \\
\hline
\end{tabular}

The table of Multiple Regression Analysis Model shows that HIV/AIDS awareness jointly predicted two percent $(2 \%)$ variance in dating behavioural pattern of University undergraduate students. This confirms that the hypothesis that HIV/AIDS Awareness has a significant influence on how and why undergraduate dates each other. Furthermore, the model revealed the individual contributions of all the four subscale of HIV/AIDS Awareness as follows: Knowledge of the occurrence and prevalence of HIV/AIDS significantly contributed approximately eight percent (8\%), Awareness of mode of transmitting HIV/AIDS significantly contributed approximately nine percent (9\%), and attitude towards preventing HIV/AIDS significantly contributed eight percent $(8 \%)$. It was noted that the subscale that measure the awareness of effects and consequences of HIV/AIDS did not contribute significantly to the predicting of variance in dating behaviour.

The results from table 12 above show that the level of general awareness of HIV/AIDS significantly predicts variance in dating behaviour of University undergraduates in South-western Nigeria. Thus, the alternate hypothesis (H1) that states that HIV/AIDS Awareness will significantly predict variance in undergraduates dating behaviour is therefore accepted.

\section{Discussion}

The research study examined the impact of HIV/AIDS Awareness on dating behaviour of undergraduates in the South-Western Nigerian universities. The respondents are group of people who could be regarded as adolescents and young adults. Specifically, the study attempted to provide valid answers to some research questions highlighted and proposed hypotheses on dating behaviour. The analyses of the data that provided answer to these research questions and hypotheses were done primarily with the aid of simple percentages, t-test and multiple regression analysis. The major findings of the study as presented in the above tables were further discussed in this section.

The significant finding of this study is that HIV/AIDS awareness has minimal influence on undergraduate dating behavior. This is because adolescents and young adults are in a period of transition into sexual awareness and interest, thus at this period, their curiosity often cause some of them to wanting to experiment sexual intercourse without considering the consequences of such behavior; however creating such awareness of the consequences which include sexually transmitted diseases (STDs) and HIV/AIDS will go a long way to influence their behaviour. This statement underscore the earlier social research findings that confirm young people to be at special risk of HIV infection as a result of their curiosity and experimentation with unprotected sexual intercourse and multiple sexual partners (Gray \& Saracino, 1989; Asuzu, 1994; Buysse, 1996; and Swart-Kruger \& Richter, 1997).

Findings from the study revealed a lot of psychosocial implications in the area of interpersonal relationship among undergraduates in south-western Nigeria. The results as shown in Tables 1 to 4 reveal different degree of awareness of the four major components of HIV/AIDS awareness but with many misconceptions. This suggests that undergraduates who participated in the study have a fair knowledge of HIV/AIDS, mode of transmission, effects and consequences of HIV/AIDS infection but a lot of misconceptions about the strategies of preventing HIV/AIDS infection, for example table 1.4 item 31 shows that the respondents have misconception about the use of vaccine in preventing the spread of HIV/AIDS. Similar studies in the past have also reported similar findings in Nigeria, Kuwait and Italy (Carducci, Frasca, Grasso, Terzi, \& Avio, 1995; Al-Owaish, Moussa, Anwar, Al-Shoumer\& Shammer, 1999; Uwalaka \& Matsuo, 2002).

In terms of general dating behaviour, the result shows (Table 5) that participant have different definitions for dating. Also, the results indicate the respondents date for reasons ranging from mate selection to gaining approval and acceptance from opposite sex. Also participants differ greatly on the activities they engage in when dating. This finding supports Okonkwo, (1999) who evaluated the psychological correlates of dating anxiety and noted that some partners engage in sexual intercourse while other date simply to avoid loneliness. It was noted that more than average number of the participants did not believe in online dating. This finding contradicts the finding of Kole, Singh, Panwar (2004) who claimed that more youths in India go online to seek their dates. The reason for this could be as a result of the fact that Nigerian youths have not fully imbibed the foreign culture of internet or on-line dating as it is being practiced in the western world.

In addition to the examination of the level of awareness of HIV/AIDS and general dating behaviour of participants, the study further examined the influence of the level of awareness of HIV/AIDS on participants' dating behaviour, seven hypotheses were tested as shown in Tables 1 to 7 . The study confirms all the hypotheses except hypothesis three that states that there will be a significant difference between the dating behaviour of undergraduates that have adequate awareness of the effects and consequences of HIV/AIDS and their counterparts that have inadequate awareness of effects and consequences of HIV/AIDS. This could be due to the 
fact majority of the participants have a lot of misconceptions about the effect and consequences of HIV/AIDS as noted above. However, the study revealed that the level of awareness of HIV/AIDS predicted two percent variance in dating behaviour. Although the percentage seems to be insignificant, yet the reality according to this finding is that the more awareness people get about HIV/AIDS the less they are likely to get themselves involved in activities that can give rise to the infection. This could further be explained by the theoretical frame-work of this study which is the attribution theory which states that how individuals think and interprete events will have impact on how they relate and behave towards the same event. Thus, change in dating behaviour can therefore be attributed to level of HIV/AIDS awareness (the knowledge, belief and attitude towards HIV/AIDS).

\section{Conclusions and Recommendations}

The pertinent question raised in the study is what impact does HIV/AIDS awareness has on undergraduates dating behaviour in Southwestern Nigeria. Thus, this study took into consideration the levels of participants' awareness of HIV/AIDS from the angle of attitude, perception and predisposition to HIV/AIDS. Furthermore, these components of HIV/AIDS awareness has been examined in relation to dating behaviour of the participants and different reasons have been adduced for variation in behaviour. However, it must be noted that variation in dating behaviour of the participants cannot only be attributed to difference in their level of HIV/AIDS awareness even though that is the focus of this study, other factors such as personality type, self esteem, environmental and socio-economic factors.

This study holds that in addition to some of the factors highlighted variables that may be responsible for variation in dating behaviour, intense effort to creating more HIV/AIDS awareness is necessary to curb the rapid increase in uncontrolled, indecent relationships and premarital sexual behaviour among the youths who are affected the most as far HIV/AIDS epidemic is concerned.

Thus the following recommendations are presented to Parents, Institutions of Learning, Media, Government and Non-Government Organizations (NGOs).

Parents: Finding from social research have shown that sex education is an issue that most parents overlook and treat with kid gloves in their day-to-day interaction with their wards. However, it is very important to discuss with the children to prevent them from been misinformed by their peers. Parents are advised to initiate planned sex education with their children as soon as they learn to identify different parts of their bodies. Parents should be well informed about issues such as general human development, sexuality, HIV/AIDS and interpersonal skills as well as sex education with their children by teaching them the proper names of their sex organ and how to maintain sanctity and assertiveness. It is also necessary that parents understand the trend of developments in their wards-biological, cognitive, emotional and psychologically as well as provide correct answers to questions posed to them by their wards without pretence or exaggeration. This will curb the curiosity associated with growing up into adulthood.

Furthermore, this study recommends that parents should learn how to build cordial relationship with their children so that they can discuss with them freely so that their wards can express themselves on issue of concern without any fear of reprimand.

Institutions of Learning: Institutions of learning which include primary, secondary school and tertiary institutions should include sex education and interpersonal relationship (dating and assertive behaviour) in their curriculum. It is expected that comprehensive sex education and interpersonal relationship (dating and assertive behaviour) would improve reproductive health and psychological wellbeing of adolescents and youths, thereby reducing the cases of unwanted pregnancy and spread of HIV/AIDS in the society.

Media: The fact that children and youths in $21^{\text {st }}$ century learn very fast from visuals and the people they see and regarded as celebrities, this study recommends that media houses and celebrities should be part of the team involve in enlightening the society at large about the danger of indecent sexual relationships and danger associated with same. Furthermore, programmes to be aired on television should be screened to avoid scenes of nudity, pornography and other related display of obscene and immoral pictures.

Government and Non-Governmental Organizations (NGOs): Government should make policies and fund such policies that support the campaigns against the spread of HIV/AIDS, premarital sexual affair and related matter. Laws should be made to curtail the problems of rape; teenage marriage and other child abuse that give rise to promiscuity and indecent living in the society at large. Non-governmental Organizations as part of their efforts should intensify their enlightenment campaign and educate the teeming youths and adolescents in the society about evils associated with premarital and unprotected sex. The study therefore, recommends that more research can be carried out on sexuality and similar topic using different participants from different geographical area of Nigeria.

\section{ACKNOWLEDGMENTS}

The researchers sincerely appreciate the support of the Management of Redeemer's University, Mowe, Ogun State Nigeria in carrying out this in-depth study in South-Western Nigeria. Thank you

\section{REFERENCES}

[1] Aiken, L.S. et al (2001). Subjective risk and health protective behavior: Cancer screening and cancer prevention. In A. Baum, T.A. Revenson \& J.E. Singer (Eds.). Handbook of 
health Psychology (PP.727-746). Mahwah, NJ: Lawrence Erlbaum Associates, Inc

[2] Al-Owaish,R.(1999). Knowledge, attitude, beliefs and practices about HIV/AIDS in Kuwait. AIDS Education and Prevention,11(2), 163-173

[3] Asuzu, M.C. (1994). Sexual beliefs, attitudes and knowledge of adolescent youths in Ibadan concerning AIDS. West African Journal of Medicine, 13(4), 245-247

[4] Bandura, A. (1991). Perceived self-efficacy in the exercise of personal agency. The Psychologist, 10, 411-424

[5] Becker, M.H., \& Maiman, L.A. (1975). So ciobehavioral determinants of compliance with health and medical care recommendations. Medical Care, 8, 10-24

[6] Buysse, A. (1996). Adolescents, young adults, and AIDS: A study of actual knowledge vs. perceives need for additional information. Journal of Youth and Adolescence, 25(2), 259-271

[7] Carducci, A., et al. (1995). AIDS related information, attitudes and behaviours among Italian male young people. $E u$ ropean Journal of Epidemiology, 11(1), 23-31

[8] Cohen, B., \& Trussell, J. (1996). Preventing and Mitigating AIDS in Sub-Saharan Africa: Research and Data Priorities for Press the Social and Behavioral Sciences. Washington, D.C.: National Academy

[9] Fantahum, M. \& Chala, F. (1996). Sexual behaviour, and knowledge and attitude towards HIV/AIDS among out of school youth in Bahir Dar Town, northwest Ethiopia. Ethiopian Medical Journal, 34(4), 233-242

[10] Fishbein, M., et al. (2001). Factors influencing behavior and behavior change. In A. Baum, T.A. Revenson \& J.E. Singer (Eds.), Handbook of Health Psychology (pp.727-746). Mahwah, NJ: Lawrence Erlbaum Associates, Inc

[11] Gray, L. \& Saracino, M. (1989). AIDS on campus: A preliminary study of college students' knowledge and behaviors. Journal of Counseling and Development, 68, 199-202

[12] Heider. F. (1958). The Psychology of interpersonal relations. New York: Wiley

[13] Hudson, W.W (1982). Index of self-esteem. The clinical measurement package: A field manual. Chicago: Dorsey press

[14] Katz, R.C., et al. (1995). Knowledge and attitudes about AIDS: A comparison of public high school students, incarcerated delinquents, and emotionally disturbed adolescents. Journal of Youth and Adolescence, 24(1), 117-131

[15] Kole, S.K.(2004). Dating and mate seeking behaviour of Indian youth in the context of HIV/AIDS: An exploratory study. International Conference on AIDS

[16] Konde-Lule, J.K et al. (1989). Knowledge, attitudes, and practices concerning AIDS in Ugandans. AIDS, 3, 513-518
[17] Levenson, R. W. \& Gottaman, J.M. (1978). Toward the assessment of social competence. Journal of Consulting and Clinical Psychology, 46, 453-462

[18] Okonkwo, C.O. (1999). The evaluation of psychological correlates of dating anxiety. Unpublished M.Sc, research project, Department of Psychology, University of Lagos

[19] Ologun, S.E., (2002) The Parameter and paradox of HIV/AIDS in Nigeria. Need for an Integrated Counselling Approach. Conference Proceedings (CASON)

[20] Omoluabi, P.F. (1995). Attitude to AIDS scale. Unpublisherd monogragh, Department of Psychology, University of Lagos

[21] Osgoog, C.E. et al. (1975). The measurement of meaning: Urbana: The University of Illinois Press

[22] Roscoe, B. \& Kruger, T.L. (1990). AIDS: Late adolescents' knowledge and its influence on sexual behavior. Adolescence, 25(97), 39-48

[23] Serovich, J.M. \& Greene, K. (1997). Predictors of adolescent sexual risk taking behaviors which put then at risk for contracting HIV. Journal of Youth and Adolescence, 26(4), $429-443$

[24] Smith, D. J (2004). Premarital sex, procreation and HIV risk in Nigeria. Studies in Family Planning 35(4): 223-235

[25] Sprecher, I.O. (1990) The Impact of the Threat of AIDS on Heterosexual Dating Relationships ; Journal of Psychology \& Human Sexuality, Volume: 3(2)29-44 ISSN: 0890-7064

[26] Swart-Kruger, J. \& Richter, L.M. (1997). AIDS-related knowledge, attitudes, and behavior among South African street youth: Reflection on power, sexuality, and autonomous self. Social Science and Medicine, 45(6), 957-966

[27] Taylor, C.C. (1990). Condoms and Cosmology: The "fractal" person and sexual risk in Rwanda. Social Science and Medicine, 31, 1023-1028

[28] United Nations. (2000). UNAIDS Report on the Global HIV/AIDS Epidemic, June

[29] Uwalaka, E. \& Matsuo, H. (2002). Impact Of Knowledge, Attitude, And Beliefs About Aids On Sexual Behavioral Change Among College Students In Nigeria: The Case Of The University Of Nigeria Nsukka. West Africa Reivew: 3, 2

[30] Vincent, A.O. (1995). A psychoeducational approach to modifying attitudes towards AIDS prevention. Unpublished B.Sc. thesis, Department of Psychology, University of Lagos

[31] Vogels, T., Brugman, E., \& van Zessan, G. (1999). AIDSrelated knowledge, attitudes, and behaviors: A comparison of Dutch students and dropouts. Adolescence, 34(134), 369-379

[32] Weiner, B. (1986). Spontaneous causal thinking. Psychological bulletin, 97,74-84 